\title{
Radiographic and Histopathologic Evaluation of L-Carnitine and Vitamin E Efficacy on Irradiated Jaw Bones
}

\author{
Amira I. Sayed ${ }^{(1)}$, Osama S. El-Shall ${ }^{(2)}$, Dina H. Salama ${ }^{(1)}$, Mai S. Attia ${ }^{(2)}$ and \\ Salwa F. Ahmed ${ }^{(1) \#}$ \\ ${ }^{(1)}$ Health Radiation Research Department, National Center for Radiation Research \\ and Technology (NCRRT), Atomic Energy Authority (AEA), Cairo, Egypt; (2)Oral \\ Medicine, Periodontology, Oral Diagnosis and Radiology Department, Faculty of \\ Dental Medicine for Girls, Al-Azhar University, Cairo, Egypt.
}

\begin{abstract}
$\mathbf{T}$ HE AIM of this study is to evaluate the efficacy of L-Carnitine and vitamin E alone or in combination on irradiated jaw bones in rats through radiographic assessment of the bone density and histopathologic examination of bone morphology. Forty male albino rats were divided randomly into 4 groups each of 10 rats. Group R represented the rats that received fractionated radiation dose (2 Gray per fraction) for one week. Groups LR, ER and LER represented the rats that received L-Carnitine $300 \mathrm{mg} / \mathrm{kg}$ via intra peritoneal injection, vitamin E $40 \mathrm{mg} / \mathrm{kg}$ via intramuscular injection or both daily for five days and then exposed to fractionated radiation 2 Gray day after day for one week after the last treatment, respectively. Data revealed a significant improvement of mandibular bone density in the groups received L-Carnitine, vitamin E alone or in combination as compared to the gamma-irradiated group. Moreover, the treated groups showed almost normal morphology of both mandibular bone and periodontal ligament in contrast to the gamma irradiated group where bone resorption and periodontal ligament degeneration and vacuolization were detected. In conclusion, gamma radiation had a deleterious effect on mandibular bone and periodontal ligament as indicated by decreased bone density and altered morphology. In addition, L-Carnitine and vitamin $\mathrm{E}$ treatment alone or in combination could, to a large extent, maintain the normal bone density and preserve the morphological architecture of mandibular bone and periodontal ligament.
\end{abstract}

Keywords: Gamma irradiation, Vitamin E, L-Carnitine, Mandible, Periodontal ligament, Bone density.

\section{Introduction}

Radiation therapy with high doses and in considerable areas involving one or more tissue component of the oral cavity, may probably develop different unwanted complications. These complications include nausea, vomiting, weight loss, mucositis, candidiasis, radiation caries, xerostomia, soft tissue necrosis and osteoradionecrosis (Jham \& da Silva Freire, 2006). Osteoradionecrosis is one of the main and most intense inflammatory reactions in response to bone ionizing radiation where radiation results in irreparable injury to the osteocytes, in addition to the microvascular system (Johnson et al., 1993 and Vissink et al., 2003). Osteoradionecrosis manifested clinically as pain, orofacial fistulas, exposed necrotic bone, pathologic fracture and suppuration (Hancock et al., 2003).

Radiation injury to surrounding normal tissues restricts the delivery of the effective dose to tumors that may reduce treatment efficiency (Hosseinimehr, 2007). There are several possible mechanisms by which a radioprotector can decrease the effect of ionizing radiations depending on many factors including radiation dose, type of exposure, oxygen tension of irradiation medium and function and structure of the tissue which is exposed to radiation (Takahashi et al., 2001). Among those radioprotectors is L-Carnitine which is a natural antioxidant widely distributed in the body (Santoro et al., 2005). It is obtained mostly from the diet or can be given exogenously.

"Corresponding author email: salwaa_fared@yahoo.com 
Also, it can be synthesized endogenously by skeletal muscle, heart, liver, kidney, and brain (Yurut-Caloglu et al., 2010). L-Carnitine is able to scavenge superoxide anion, to inhibit the lipid peroxidation (Rani \& Panneerselvam, 2002) and to enhance non-enzymatic antioxidants, such as vitamin E (Rani \& Panneerselvam, 2001). Vitamin E, another antioxidant radioprotector, is one of the free radical scavenger that scavenges many radicals thus preventing damage to cell structures (Wolf et al., 1998). It has a powerful anti-inflammatory effect beside its stabilization of membrane permeability and fluidity (Karslioglu et al., 2004). Vitamin E has a dual ability to reduce apoptosis of normal tissues on top of detrimental status (Osakada et al., 2003) and in the same time it enhances apoptosis of cancer cells (Neuzil et al., 2004).

L-Carnitine and vitamin E have wellestablished radioprotective effects on liver and bone marrow (Alam et al., 2010), brain and retina (Sezen et al., 2008), salivary gland function (Ramos et al., 2006) and growing bone (YurutCaloglu et al., 2010). However, their effects on bone density and morphology of jaw bones were limited. So, the aim of this study is to evaluate the efficacy of L-Carnitine and vitamin E separately or in combination on irradiated jaw bones in rats through radiographic assessment of the bone density and histopathologic examination of the bone.

\section{Experimental}

A total number of 40 male Albino rats ranging from $120-150 \mathrm{~g}$ were used in this study. The animals were housed in especially designed cages ( 5 rats per cage), in a room with a $12-\mathrm{h}$ daynight cycle, temperature of $24-28^{\circ} \mathrm{C}$, humidity of $45-64 \%$. All animals were fed semi purified diet and water ad libitum for 10 days before the start of the experiment. The animals were investigated following the rules and regulations of the animal experimental studies approved by ethical committee of Faculty of Dental Medicine for Girls, AL-Azhar University- Girls' Branch, including their facilities diet and method of scarification.

The rats were divided randomly into 4 groups 10 rats each. Radiation group ( $R)$ where rats received fractionated radiation (6 Gray); 2 Gray day after day three times a week (Alam et al.,
2010). L-Carnitine (LR), vitamin E (ER) and combination (LER) groups where rats were treated with L-Carnitine (L-Carnitine hydrochloridesynthetic, $\geq 98 \%$, Sigma-Aldrich, Italy) $300 \mathrm{mg} /$ $\mathrm{kg}$ via intra peritoneal injection (Yurut-Caloglu et al., 2010), vitamin E (( \pm )- $\alpha$-Tocopherol-synthetic, $\geq 96 \%$ (HPLC), Sigma-Aldrich, Germany) $40 \mathrm{mg} /$ $\mathrm{kg}$ intramuscular (Üçüncü et al., 2006) and the combination of both treatment daily for five days, respectively and then exposed to fractionated radiation (6 Gray); 2 Gray day after day for one week starting $30 \mathrm{~min}$ after last treatment. Group LER in which rats received both L-Carnitine $300 \mathrm{mg} / \mathrm{kg}$ vitamin $\mathrm{E} 40 \mathrm{mg} / \mathrm{kg}$ intramuscular daily for five days and then exposed to fractionated radiation (6 Gray); 2 Gray day after day for one week $30 \mathrm{~min}$ after the last treatment. Irradiation of animals was performed at the National Center for Radiation Research and Technology (NCRRT), Cairo, Egypt using 137Cs Gamma Cell 40 at a dose rate of $0.689 \mathrm{rad} / \mathrm{sec}$ at the time of experiment.

Five rats from each group were sacrificed by decapitation 1 week and 2 weeks after radiation exposure. The skin was removed then the mandible was carefully dissected. The left sides were used for determination of bone density while the right ones were prepared for histopathological analysis. The collected left mandibles were imaged by periapical radiographs. An indirect digital image radiographic system; the DBS-Win software, which is a part of vista scan system (Dürr Dental GmbH \& Co. KG, Höpfigheimer Straße 17. 74321 Bietigheim- Bissingen/ Germany) was followed in this study to obtain and calculate bone density using the image processing software. Densitometric analysis of periapical radiographs provides valuable information about the degree of bone mineralization. The term density refers to the degree of whiteness of the dental image. The dental image consists of points or pixels, each having a certain density value. The density value is between 0 and 256; the greater the value, the brighter (white) the pixel. The collected right mandibles were fixed in $10 \%$ formalin and then were decalcified in $10 \%$ formic acid for 7 days. After processing the tissues in alcohol, all tissues were embedded into paraffin and five micrometer thick sections were cut and stained with hematoxylin-eosin.

Data were collected, revised, coded and entered to the Statistical Package for Social Science (IBM SPSS) version 23. The quantitative data were 
presented as mean and standard deviations. The comparison between two independent groups with quantitative data and parametric distribution was done using Independent t-test. The comparison between more than two independent groups with quantitative data and parametric distribution was conducted using One Way ANOVA test followed by post hoc analysis using LSD test. The confidence interval was set to $95 \%$ and the margin of error accepted was set to $5 \%$.

\section{Results}

Bone density and radiographic analysis

It was found that the $\mathrm{R}$ group recorded the lowest mandibular bone density mean value one and two weeks after radiation $(26.20 \pm 3.56$ and $27.00 \pm 3.81$, respectively), while the LER group recorded the highest mandibular bone density mean value $(35.20 \pm 2.17$ and $35.40 \pm 2.79$, respectively) compared to all groups. Data of the bone density one week after radiation revealed the presence of a highly significant difference between $\mathrm{R}$ and either LR or LER groups (P-value $<0.01$ ), while there was a significant difference between $\mathrm{R}$ and ER groups ( $\mathrm{P}$-value $<0.05)$. Bone density measured two weeks after radiation revealed that there was a highly significant difference between $\mathrm{R}$ and either ER or LER groups (P-value $<0.01$ ), while there was a significant difference between $\mathrm{R}$ and LR groups ( $\mathrm{P}$-value $<0.05$ ) (Table 1 and Fig. 1-3).

TABLE 1. The mean mandibular bone density $\left(\mathrm{gm} / \mathrm{cm}^{2}\right)$ of different groups one and two weeks after radiation exposure.

\begin{tabular}{lcccc}
\hline & \multicolumn{2}{c}{ 1 week } & \multicolumn{2}{c}{ 2 weeks } \\
\cline { 2 - 5 } & Mean \pm SD & P-value & Mean \pm SD & P-value \\
\hline R group & $26.20 \pm 3.56$ & & $27.00 \pm 3.81$ & \\
LR group & $34.40 \pm 2.07^{* *}$ & 0.002 & $34.80 \pm 3.77 *$ & 0.012 \\
ER group & $33.80 \pm 3.70^{*}$ & 0.011 & $34.40 \pm 1.95 * *$ & 0.005 \\
LER group & $35.20 \pm 2.17^{* *}$ & 0.001 & $35.40 \pm 2.79 * *$ & 0.004 \\
\hline
\end{tabular}

(*) Means significant difference as compared to $\mathrm{R}$ group.

$(* *)$ Means highly significant difference as compared to R group.

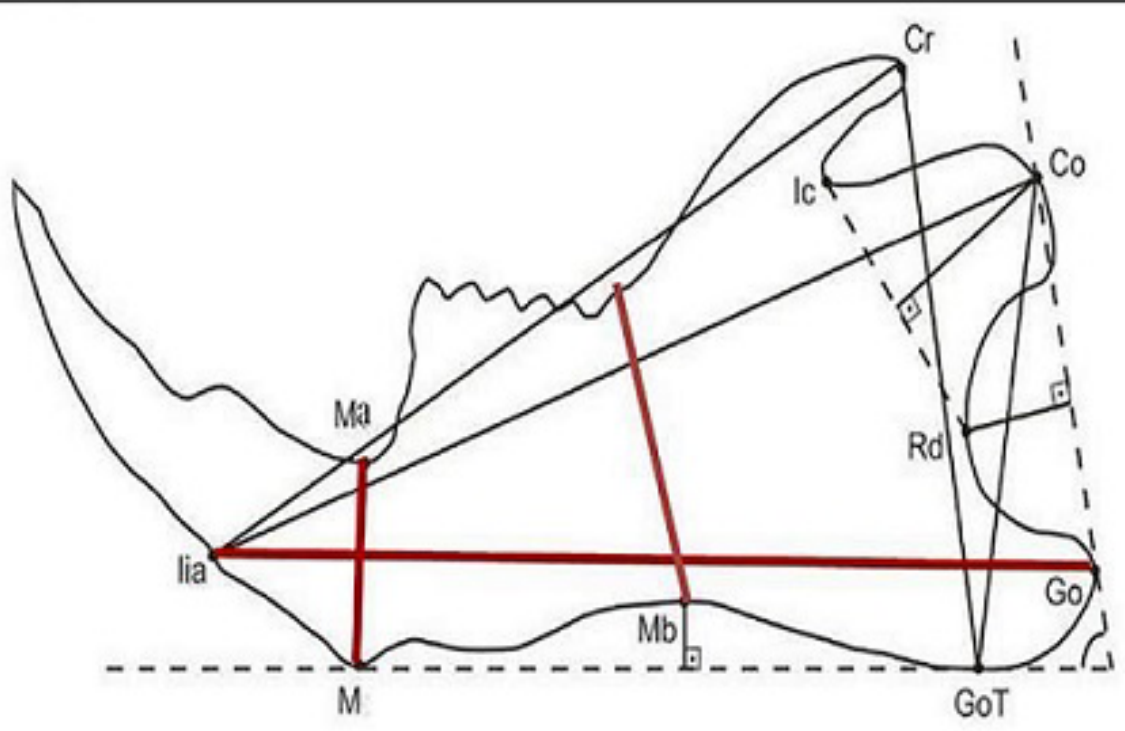

Fig. 1. The anatomical lines delineated on the radiographs of the rat mandible to measure the bone density, where lia-Go line is extending from the alveolar point of the mandibular incisor (the lowest point of the buccal alveolar bone contour of the mandibular incisor) to gonium (the most posterior point of the mandibular angle contour), Ma-M line is extending from mandibular alveolar point (the deepest point of the upper part of the alveolar crest between the mandibular incisors and first molar) to menton (the lowest point on the mental symphysis contour) while the $\mathrm{Mb}$ line was extending from Intersection of ascending ramus with tooth row to mandibular base (the deepest point of the mandibular base concavity). 


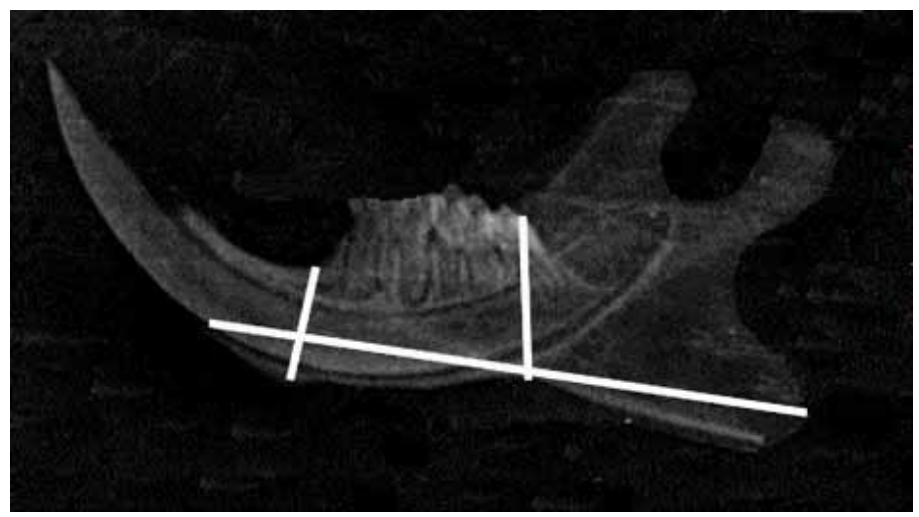

Fig. 2. Radiographic presentation of the selected three lines used to measure density.

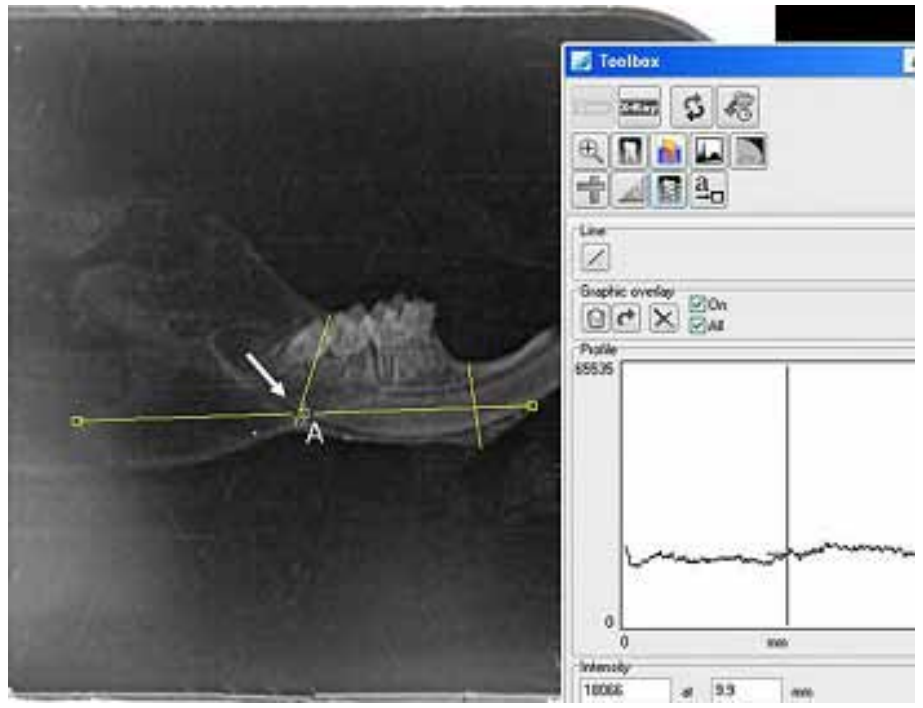

Fig. 3.The bone density graph at point $A$ (white arrow), where the measurements indicates decreased bone density at this point $=0.27 \mathrm{gm} \backslash \mathrm{cm}^{2}$ and the three anatomical lines are drawn.

\section{Histopathological analysis}

One week after irradiation, the gammairradiated mandibular bone showed normal Haversian canal and decreased number of osteocytes. The bone surface facing the periodontal ligament was scalloped indicating bone resorption. Periodontal ligament vacuolization, disarranged collagen fiber and areas of degeneration were detected (Fig. 4 A). The mandibular bone of the L-Carnitine treated group (LR) expressed decreased osteocytes number. The Haversian canals were normal. The alveolar process was normal in size having almost smooth bone surface facing the periodontal ligament with limited areas of bone resorption. The periodontal ligament was hyalinized with many areas of degeneration (Fig. $4 \mathrm{~B}$ ). In ER group, the bone showed some normal osteocytes while the other had empty lacuna, Haversian canals contained blood vessels and connective tissue. The bone surface facing the periodontal ligament was irregular and scalloped indicating bone resorption. The periodontal ligament showed mild vacuolization and slight degeneration (Fig. 4 C). Combined treatment with L-Carnitine and vitamin E preserved the architecture of the cortical plate of the alveolar process. The alveolar bone surface facing the periodontal ligament was smooth. The Haversian canals were normal while the osteocytes showed a slight decrease of their number. The periodontal ligament was almost normal with very mild vacuolization (Fig. $4 \mathrm{D}$ ).

Fourteen days after irradiation, the gammairradiated mandibular bone showed a decreased bone cells number, loss of nuclei, massive bone resorption and reduction of bone thickness. The periodontal ligament revealed a deep extension into the bone, sever vacuolization and 
homogenization of collagen fibers (Fig. 5 A). The mandibular bone of the L-Carnitine treated group (LR) exhibited a normal osteocyte in their lacunae with normal haversian canals. The bone surface showed evidence of bone resorption. There were many reversal lines indicating bone formation. The periodontal ligament showed mild vacuolization (Fig. 5 B). In the ER group, the alveolar process showed decreased osteocytes with a slight irregular bone surface facing the periodontal ligament. There were many reversal lines indicating bone remodeling. The periodontal ligament was hyalinized (Fig. $5 \mathrm{C}$ ). The bone demonstrated normal osteocytes and haversian canals. There were many reversal lines denoting bone remodeling. The periodontal ligament showed a sign of hyalinization and degeneration (Fig. 5 D).

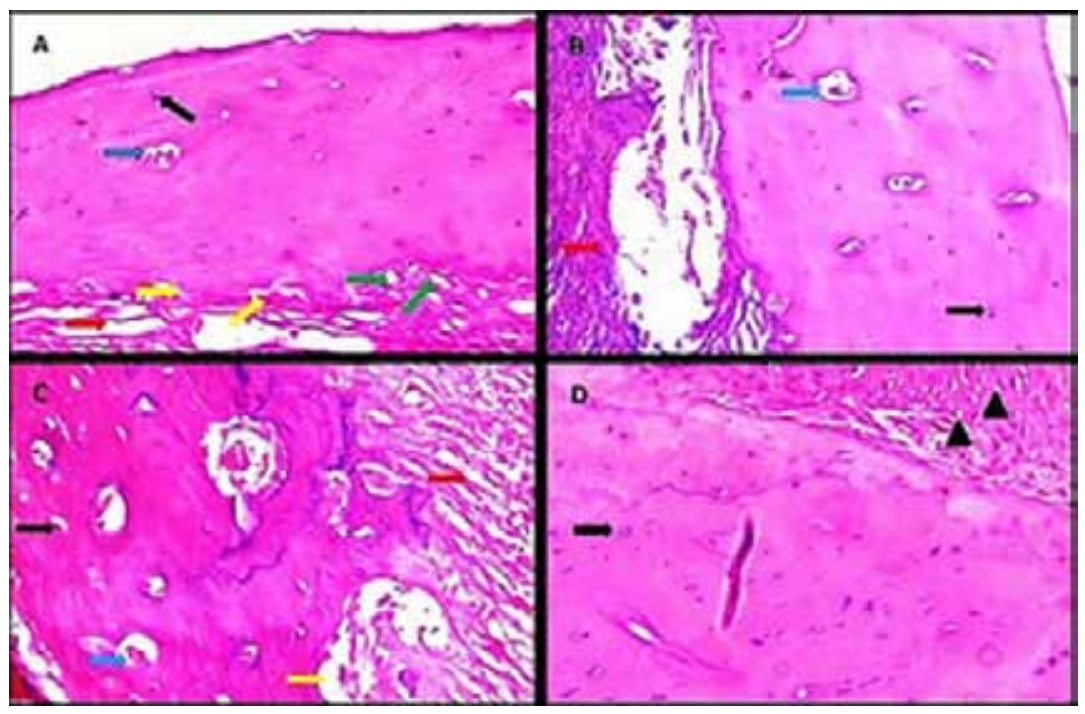

Fig. 4. Photomicrograph of mandibular bone one week post-irradiation $A, B, C$ and $D$ of groups $R, L R, E R$ and LER, respectively showing normal osteocyte (black arrow), haversian canal (blue arrow), scalloped alveolar bone surface facing the periodontal ligament (yellow arrows), periodontal ligament vacuolization green arrows), degenerated and hyalinized collagen fibers (red arrows) and normal periodontal ligament with very mild vacuolization (arrow heads) (H. \& E. x200).

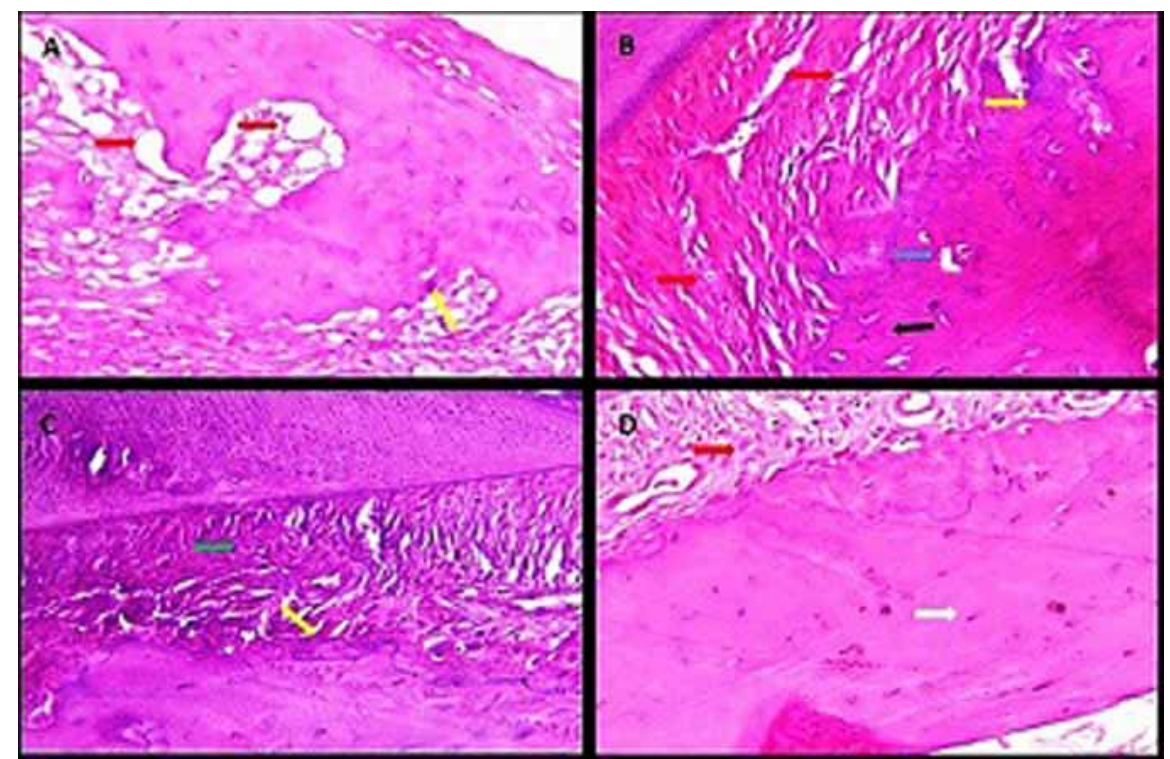

Fig. 5. Photomicrograph of mandibular bone one week post-irradiation $A, B, C$ and $D$ of groups $R, L R, E R$ and LER, respectively showing bone resorption (yellow arrows), periodontal ligament vacuolization (red arrows), normal osteocyte (black arrow), haversian canal (blue arrow), hyalinized periodontal ligament (green arrow) and normal alveolar bone (white arrow) (H. \& E. x200). 


\section{Discussion}

Head and neck cancer is a heterogeneous group of neoplasms that share a common anatomic origin including carcinomas of the salivary glands, oral cavity, nasal cavity, lip, pharynx and larynx (Joseph \& D'Souza, 2012). The majority of head and neck cancer patients need radiotherapy at one point during treatment. Cells exhibit different levels of radiosensitivity depending on their stage in the cell cycle at the time of radiation. Normal cells have a greater capacity than tumor cells to repair the radiation damage, especially at low doses. This makes fractionated radiotherapy efficient in sparing normal tissue (Vissink et al., 2003).

In the present study, gamma radiation induced a reduction of bone cells, osteoblastic resorption ending with reduced bone thickness. Similarly, irradiation induced progressive occlusion and obliteration of small vessels leading to reduced cell number, hypovascularity, fibrosis and fatty degeneration of the bone marrow (Vissink et al., 2003). Hypoplasia or aplasia of bone marrow is thus common after standard fractionated radiotherapy. The hematopoietic cells are decreased or absent and replaced by adipocytes. As a result, the bone marrow turns pale as the yellow-colored adipocytes replace the normal red hematopoietic marrow (Fajardo, 2005). Irradiation results in demineralization of bone, thinning of bones, sclerosis and loss of trabecular connections has been described following radiotherapy (Hopewell, 2003). Thickening of trabeculae within the irradiated volume can be observed within the irradiated volume (Williams \& Davies, 2006). This coarsening of trabeculae is also observed from the marrow cavity of various animal models within weeks of exposure (Fajardo, 2005). In addition, there has been observed an increase in early osteoclast activity when mice are irradiated with a 0.5 -Gy dose of iron ions during limb disuse, modelling the reduced loading of the spaceflight environment (Yumoto et al., 2010). Quantitatively, a significant $(\sim 30 \%)$ reduction in bone mineral density was observed following pelvic irradiation with either 45Gy or 22.5Gy total dose of highenergy photons (Nishiyama, 1992). Reduction in bone mass and overall bone quality is dependent on several factors, including the dose absorbed, the energy of the radiation beam, the fraction size of the radiation dose and the age and developmental stage of the patient (Williams \& Davies, 2006).
L-Carnitine and vitamin E separately or in combination were found to maintain the mandibular bone density normal in addition to preserving the mandibular bone and periodontal ligament morphology. These results were in accordance with those of Patano et al. (2008) who have suggested that L-Carnitine has positive effects on osteoporosis and bone mineral density. Hooshmand et al. (2008) stated that L-Carnitine application in rats following ovariectomy significantly increased bone mineral density in tibia and concluded that L-Carnitine may also similarly increase bone mineral density by lowering the rate of bone turnover. Similarly, Orsal et al. (2013) found that L-Carnitine had the ability for bone mineral density restoration in ovariectomised rats. Benvenga et al. (2001) reported that oral intake of L-Carnitine increased bone mineral density and that L-Carnitine had a positive effect on bone mineralization in hyperthyroid patients. L-Carnitine has also shown anabolic effects in a few studies using either osteoblasts or bone marrow cells (Benvenga et al., 2004 and Colucci et al., 2005). Another human study reported that L-Carnitine enhanced bone mineral density. Moreover, they suggested that L-Carnitine had anti-fracture effect in osteoporotic men (Lei \& Chuan, 2015). L-Carnitine is a substance that can act as an antioxidant and free radical scavenger (Hagen et al., 2002). In addition, L-Carnitine has the capacity to control carbohydrate metabolism to maintain cell membrane structure and cell viability and it is an essential cofactor in the oxidation of long-chain fatty acids (Athanassakis et al., 2001).

Similarly, Shuid et al. (2010) have shown that supplementation with vitamin $\mathrm{E}$ enhances femoral strength has evidenced by enhanced ultimate and yield load and stress in young male rats. Furthermore, vitamin $\mathrm{E}$ was able to dosedependently increase serum alkaline phosphatase concentrations, a non-specific biomarker of bone formation expressed in the osteoblastic plasma membrane alkaline phosphatase (Smith et al., 2005). Some studies suggest that alpha-tocopherol may improve bone quality and maintain bone mineral density (Norazlina et al., 2000) decrease bone resorption (Ahmad et al., 2005) and increase bone formation (Mehat et al., 2010). Vitamin E decreases bone resorption as indicated by reducing osteoclast activity. Feresin et al. (2013) found that vitamin $\mathrm{E}$ failed to ameliorate ovariectomy induced bone mineral density reduction and loss 
of cancellous bone volume. On the other hand, it significantly suppressed bone resorption markers. One of the mechanisms by which vitamin $\mathrm{E}$ affects bone health is through its anti-inflammatory and anti-oxidative properties. The role of vitamin $\mathrm{E}$ in these processes has been clearly identified and is significant in the prevention of chronic diseases including atherosclerosis (Chai \& Arjmandi, 2011) and cancer (Dutta \& Dutta, 2003). Hypothesized mechanisms include preventing the accumulation of bone resorbing cytokines (Hermizi et al., 2009) reducing the number of osteoclasts and increasing the number of osteoblasts (Mehat et al., 2010).

\section{Conclusion}

The results of the present study revealed that gamma radiation has a deleterious effect on mandibular bone and periodontal ligament as indicated by decreased bone density and altered morphology. In addition, L-Carnitine and vitamin E treatment separately or in combination before radiation exposure could, to a large extent, maintain the normal bone density and preserve the morphological architecture of mandibular bone and periodontal ligament.

\section{Disclosure of Interests}

The authors report no conflicts of interests.

\section{References}

Ahmad, N.S., Khalid, B.A.K., Luke, D.A. and Ima Nirwana, S. (2005) Tocotrienol offers better protection than tocopherol from free radical-induced damage of rat bone. Clin. Exp. Pharmacol. Physiol. 32(9), 761-770.

Alam, S.S., Hassan, A.M., El Halawaney, N.K., ElNashar, D.E. and El-Azeem, M.G.A. (2010) Radioprotective activity of L-Carnitine and $\alpha$-Lipoic acid against whole body $\gamma$-irradiation in rats. $J . A m$. Sci. 12, 6 .

Athanassakis, I., Mouratidou, M., Sakka, P., Evangeliou, A., Spilioti, M. and Vassiliadis, S. (2001) L-Carnitine modifies the humoral immune response in mice after in vitro or in vivo treatment. Int. Immunopharmacol. 1(9-10), 1813-1822.

Benvenga, S., Ruggeri, R.M., Russo, A., Lapa, D., Campenni, A. and Trimarchi, F. (2001) Usefulness of L-Carnitine, a naturally occurring peripheral antagonist of thyroid hormone action, in iatrogenic hyperthyroidism: a randomized, double-blind, placebo-controlled clinical trial. J. Clin. Endocrinol. Metab. 86(8), 3579-3594.

Benvenga, S., Amato, A., Calvani, M. and Trimarchi, F. (2004) Effects of carnitine on thyroid hormone action. Ann. N Y Acad. Sci. 1033(1), 158-167.

Chai, S.C., and Arjmandi, B.H. (2011) Vitamin E dosedependently reduces aortic fatty lesion formation in orchidectomized aged rats. Aging. Clin. Exp. Res. 23(1), 11-16.

Colucci, S., Mori, G., Vaira, S., Brunetti, G., Greco, G., Mancini, L. Simon G. M., Sardelli, F., Koverech, A., Zallone, A. and Grano, M. (2005) L-Carnitine and isovaleryl L-carnitine fumarate positively affect human osteoblast proliferation and differentiation in vitro. Calcif. Tissue Int. 76(6), 458-465.

Dutta, A. and Dutta, S.K. (2003) Vitamin E and its role in the prevention of atherosclerosis and carcinogenesis: a review. J. Am. Coll. Nutr. 22(4), 258-268.

Fajardo, L.F. (2005) The pathology of ionizing radiation as defined by morphologic patterns. Acta Oncol. 44(1), 13-22.

Feresin, R.G., Johnson, S.A., Elam, M.L., Kim, J.S., Khalil, D.A., Lucas, E.A., Smith, B.J., Payton, M.E., Akhter, M.P. and Arjmandi, B.H. (2013) Effects of vitamin $\mathrm{E}$ on bone biomechanical and histomorphometric parameters in ovariectomized rats. J. Osteoporos. Article ID 825985, 9 pages.

Hagen, T.M., Liu, J., Lykkesfeldt, J., Wehr, C.M., Ingersoll, R.T., Vinarsky, V. and Ames, B.N. (2002) Feeding acetyl-L-Carnitine and lipoic acid to old rats significantly improves metabolic function while decreasing oxidative stress. Proc. Natl. Acad. Sci. 99(4), 1870-1875.

Hancock, P.J., Epstein, J.B. and Sadler, G.R. (2003) Oral and dental management related to radiation therapy for head and neck cancer. J. Can. Dent. Assoc. 69(9), 585-590.

Hermizi, H., Faizah, O., Ima-Nirwana, S., Nazrun, S.A. and Norazlina, M. (2009) Beneficial effects of tocotrienol and tocopherol on bone histomorphometric parameters in Sprague-Dawley male rats after nicotine cessation. Calcif. Tissue Int. 84(1), 65-74. 
Hooshmand, S., Balakrishnan, A., Clark, R.M., Owen, K.Q., Koo, S.I. and Arjmandi, B.H. (2008) Dietary L-Carnitine supplementation improves bone mineral density by suppressing bone turnover in aged ovariectomized rats. Phytomedicine, 15(8), 595-601.

Hopewell, J.W. (2003) Radiation-therapy effects on bone density. Pediatr Blood Cancer, 41(3), 208-211.

Hosseinimehr, S.J. (2007) Trends in the development of radioprotective agents. Drug Discov. Today, 12(1920), 794-805.

Jham, B.C. and Freire, A.R.D.S. (2006) Oral complications of radiotherapy in the head and neck. Rev. Bras. Otorrinolaringol, 72(5), 704-708.

Johnson, J.T., Ferretti, G.A., Nethery, W.J., Valdez, I.H., Fox, P.C., Ng, D., Muscoplat, C.C. and Gallagher, S.C. (1993) Oral pilocarpine for post-irradiation xerostomia in patients with head and neck cancer. N Engl. J. Med. 329(6), 390-395.

Joseph, A.W. and D'Souza, G. (2012) Epidemiology of human papillomavirus-related head and neck cancer. Otolaryngol. Clin. North Am. 45(4), 739-764.

Karslioglu, I., Ertekin, M.V., Kocer, I., Taysi, S., Sezen, O., Gepdiremen, A. and Balci, E. (2004) Protective role of intramuscularly administered vitamin $\mathrm{E}$ on the levels of lipid peroxidation and the activities of antioxidant enzymes in the lens of rats made cataractous with gamma-irradiation. Eur. J. Ophthalmol. 14(6), 478-485.

Lei, W. and Chuan, W. (2015) Efficacy of L-Carnitine in the Treatment of Osteoporosis in Men. Int. J. Pharmacol. 11(2), 148-151.

Mehat, M.Z. Shuid, A.N., Mohamed, N., Muhammad, N. and Soelaiman, I.N. (2010) Beneficial effects of vitamin $\mathrm{E}$ isomer supplementation on static and dynamic bone histomorphometry parameters in normal male rats. J. Bone Miner. Metab. 28(5), 503-509.

Neuzil, J., Tomasetti, M., Mellick, A.S., Alleva, R., Salvatore, B.A., Birringer, M. and Fariss, M.W. (2004) Vitamin E analogues: a new class of inducers of apoptosis with selective anti-cancer effects. Curr. Cancer Drug Targets, 4(4), 355-372.

Nishiyama, K., Inaba, F., Higashihara, T., Kitatani, K. and Kozuka, T. (1992) Radiation osteoporosisan assessment using single energy quantitative computed tomography. Eur. Radiol. 2(4), 322-325.

Norazlina, M., Ima-Nirwana, S., Gapor, M.T. and Khalid, B.A.K. (2000) Palm vitamin E is comparable to $\alpha$-tocopherol in maintaining bone mineral density in ovariectomized female rats. Exp. Clin. Endocrinol. Diabetes, 108(04), 305-310.

Orsal, E., Halici, Z., Bayir, Y., Cadirci, E., Bilen, H., Ferah, I., Aydin, A., Ozkanlar, S., Ayan, A.K., Seven, B. and Ozaltin, S. (2013) The role of carnitine on ovariectomy and inflammation-induced osteoporosis in rats. Exp. Biol. Med. 238(12), 14061412.

Osakada, F., Hashino, A., Kume, T., Katsuki, H., Kaneko, S. and Akaike, A. (2003) Neuroprotective effects of $\alpha$-tocopherol on oxidative stress in rat striatal cultures. Eur. J. Pharmacol. 465(1-2), 15-22.

Patano, N., Mancini, L., Settanni, M.P., Strippoli, M., Brunetti, G., Greco, G. and Colucci, S. (2008) L-Carnitine fumarate and isovaleryl-1-carnitine fumarate accelerate the recovery of bone volume/ total volume ratio after experimentally induced osteoporosis in pregnant mice. Calcif. Tissue Int. 82(3), 221-228.

Ramos, F.M., Pontual, M.L., de Almeida, S.M., Bóscolo, F.N., Tabchoury, C.P. and Novaes, P.D. (2006) Evaluation of radioprotective effect of vitamin $\mathrm{E}$ in salivary dysfunction in irradiated rats. Arch. Oral Biol. 51(2), 96-101.

Rani, P.J.A. and Panneerselvam, C. (2001) Carnitine as a free radical scavenger in aging. Exp. Gerontol. 36(10), 1713-1726.

Rani, P.J.A. and Panneerselvam, C. (2002) Effect of L-Carnitine on brain lipid peroxidation and antioxidant enzymes in old rats. J. Gerontol. A Biol. Sci. Med. Sci. 57(4), B134-B137.

Santoro, A., Lioi, M.B., Monfregola, J., Salzano, S., Barbieri, R. and Ursini, M.V. (2005) L-Carnitine protects mammalian cells from chromosome aberrations but not from inhibition of cell proliferation induced by hydrogen peroxide. Mutat. Res. Genet. Toxicol. Environ. Mutagen, 587(1), 1625.

Sezen, O., Ertekin, M.V., Demircan, B., Karslıoğlu, 
İ., Erdoğan, F., Koçer, İ. and Gepdiremen, A. (2008) Vitamin E and L-Carnitine, separately or in combination, in the prevention of radiation-induced brain and retinal damages. Neurosurg. Rev. 31(2), 205-213.

Shuid, A.N., Mehat, Z., Mohamed, N., Muhammad, N. and Soelaiman, I.N. (2010) Vitamin E exhibits bone anabolic actions in normal male rats. J. Bone Miner. Metab. 28(2), 149-156.

Smith, B.J., Lucas, E.A., Turner, R.T., Evans, G.L., Lerner, M.R., Brackett, D.J., Stoecker, B.J. and Arjmandi, B.H. (2005) Vitamin E provides protection for bone in mature hindlimb unloaded male rats. Calcif. Tissue Int. 76(4), 272-279.

Takahashi, H., Hashimoto, Y., Aoki, N., Kinouchi, M., Ishida-Yamamoto, A. and Iizuka, H. (2000) Copper, zinc-superoxide dismutase protects from ultraviolet B-induced apoptosis of SV40transformed human keratinocytes: the protection is associated with the increased levels of antioxidant enzymes. J. Dermatol. Sci. 23(1), 12-21.

Üçüncü, H., Ertekin, M.V., Yörük, Ö., Sezen, O., Özkan, A., Erdoğan, F., Kızıltunç, A. and Gündoğdu, C. (2006) Vitamin E and L-Carnitine, separately or in combination, in the prevention of radiation-induced oral mucositis and myelosuppression: a controlled study in a rat model. J. Rad. Res. 47(1), 91-102.
Vissink, A., Jansma, J., Spijkervet, F.K.L., Burlage, F.R. and Coppes, R.P. (2003) Oral sequelae of head and neck radiotherapy. Crit. Rev. Oral Biol. Med. 14(3), 199-212.

Williams, H.J. and Davies, A.M. (2006) The effect of X-rays on bone: a pictorial review. Eur. Radiol. 16(3), 619-633.

Wolf, R., Wolf, D. and Ruocco, V. (1998) Vitamin E: the radical protector. J. Eur. Acad. Dermatol. Venereol. 10(2), 103-117.

Yumoto, K., Globus, R.K., Mojarrab, R., Arakaki, J., Wang, A., Searby, N.D. and Limoli, C.L. (2010) Short-term effects of whole-body exposure to $56 \mathrm{Fe}$ ions in combination with musculoskeletal disuse on bone cells. Radiat. Res. 173(4), 494-504.

Yurut-Caloglu, V., Durmus-Altun, G., Caloglu, M., Usta, U., Saynak, M., Uzal, C. and Kocak, Z. (2010) Comparison of protective effects of L-Carnitine and amifostine on radiation-induced toxicity to growing bone: histopathology and Scintigraphy findings. Asian. Pac. J. Cancer Prev. 11(3), 661-7.

(Received 25/11/2018; accepted 17/ 1/2019) 


\section{تقييم إثعاعى و هستوباثولوجى لفاعلية ل-كارنيتين و فيتامين هـ على عظام الفك المتعرض

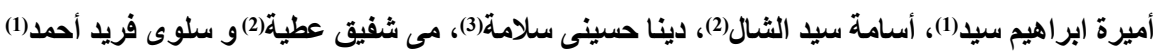

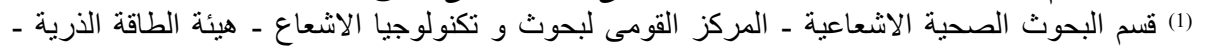

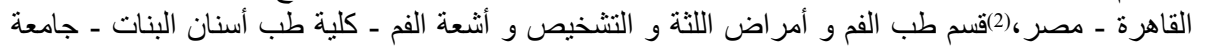

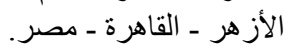

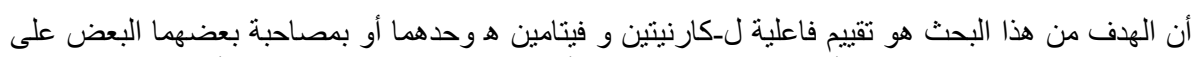

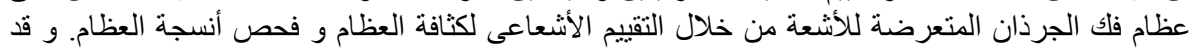

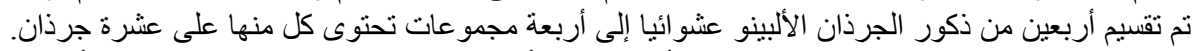

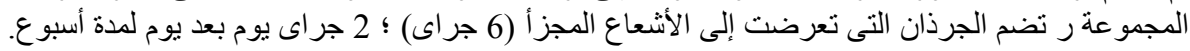

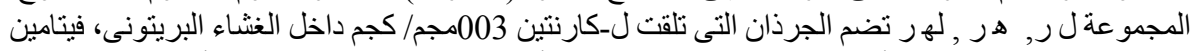

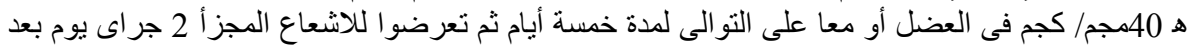

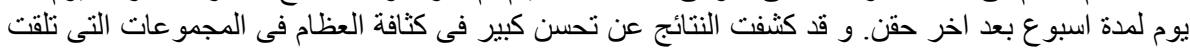

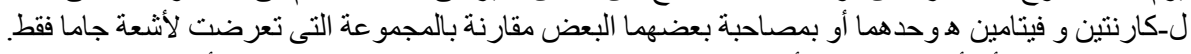

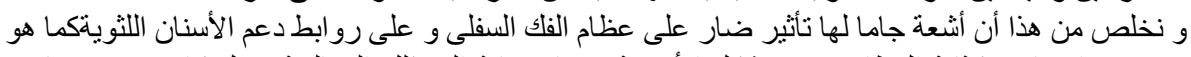

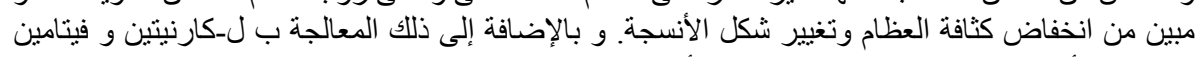

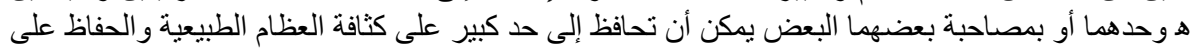
العمارة الدورفولوجية لعظام الفكك السفلي ورو ابط دعم الأسنان اللثوية. 